\title{
Fruit Quality Characters and Their Relation With Weight Per Fruit in Mango Over Years
}

\author{
A.K. BARHOLIA* and SANGEETA YADAV \\ Rajmata Vijayaraje Scindia Krishi Vishwa Vidyalaya, \\ R. A. K. College of Agriculture, Sehore 466 001, India. \\ *Corresponding authors E-mail: dr.arunbarholia@gmail.com \\ http://dx.doi.org/10.13005/ojc/300365
}

(Received: May 20, 2014; Accepted: June 15, 2014)

\begin{abstract}
Forty-eight genotypes including 31 landraces of Bhopal division, 15 commercial varieties and 2 hybrids were evaluated for quality traits in mango in two subsequent years. Amrapali, Dashehari, Alphonso, Mallika, Chousa, Bombay Green, Sehroli, SBM 01-1, SBM 01-9, SBM 01-10, SBM 01-11, SBM 01-12, SBM 01-35, SBM 01-36 possessed better skin and pulp colour, high total soluble solids, reducing and non-reducing sugars, low acidity and high ascorbic acid contents, thus, appeared promising for table consumption. SBM 01-2, SBM 01-3, SBM 01-4, SBM 01-20 and SBM 01-22 having high total acidity and high total chlorophylls were found suitable for pickle purpose. Reducing sugar and total soluble solids were positive and significantly correlated with fruit weight. Similarly, total soluble solids were positively and significantly associated with reducing sugar, non-reducing sugar, total sugars and total sugars to total acidity ratio. Reducing sugar, non-reducing sugar and total sugars were also positively and significantly associated among themselves. Among these characters, total soluble solids, reducing sugar, non-reducing sugar, total sugars to total acidity ratio exerted directpositive bearing on the fruit weight in mango. Thus, these quality traits can be modified genetically and simultaneously along with fruit weight in mango.
\end{abstract}

Key words: Fruit quality, Mango varieties, Bhopal division.

\section{INTRODUCTION}

Mango, the native of India, possesses rich genetic diversity in fruits. However, almost all the edible cultivars of mango have been developed through selection from naturally cross-pollinated seedlings except a few recent hybrids (Gupta et al. 1996 and Raiet al. 2001). The implementation of WTO regime has opened new areas for fruit export.
The increasing internal and global demand thus, warrants the development of the varieties with better fruit quality and yield potential. It also alarms the identification of desirable traits in available landraces for their registration to harvest the benefits of PVR. In the present study, an attempt was therefore, made to determine the fruit quality characteristics and their relation with weight per fruit in mango cultivars grown in Bhopal division of Madhya Pradesh. The relative 
merits of quality fruit characters were determined using path coefficient analysis for simultaneous improvement in fruit yield and quality traits in mango.

\section{MATERIALS AND METHODS}

Forty eight genotypes comprising 31 landraces from Bhopal division of Madhya Pradesh, 15 improved varieties and 02 hybrids of mango were selected for this study based on popular fruit characters like fruit size, suitability for pickles, sucking and table purposes, peel colour, firmness of pulp, flavor and storability. These genotypes were evaluated for quality characters of fruit in randomized complete block design with three replications in two subsequent on and off years. Two trees per genotype were randomly selected in each replication after fruit set. The fruits of selected trees were collected from each genotype in each replication at full maturity stage and subjected to ripening for recording observations on quality parameters. The pulp of selected fruits were bulked and three composite samples were drawn for recording observations on total soluble solids, total acidity, total sugar, reducing sugar, non-reducing sugar and total sugars to total acidity ratio. Total soluble solids were estimated by the method of Saini et al., (2001). The method given by Jayraman (1981) was adopted for estimation of total acidity. Phenol-sulphuric acid method given by Dubois et al., (1956) was adopted for estimation of total sugar. Reducing sugar was determined by the methods of Plummer (1999). The methods described in A.O.A.C. (1970) were followed for the estimation of rest of the quality parameters. Computer software SPAR 1 was used for the computation of correlation and path coefficient analysis.

\section{RESULTS AND DISCUSSION}

Analysis of variance showed significant differences among the genotypes for all the quality characters of fruits. It indicates the existence of considerable variability for all the studied characters and thus, offers good scope for the selection of desirable genotypes. The mean square due to years was also significant for chlorophyll b. The genotype $x$ environment interaction was highly significant for reducing sugar, chlorophyll a, chlorophyll b and total chlorophylls. Shrivastavaet al. (1987), Yadavet al. (1995) and Singh (2002) Dwivedi and Mitra (2003)have also reported significant variability for chemical constitution and ratio indices of the fruits. The existence of significant genotype $x$ environment interaction for reducing sugar, total sugars, chlorophyll a, chlorophyll b and total chlorophylls have also been reported by Yadavet al. (1995) and Singh (2002).

Mean, ranged best five genotypes for quality characters are mentioned in Table 1 . The total soluble solids was low $(<15 \%)$, medium (15$20 \%$ ) and high (>20\%) in twenty three, eighteen and seven genotypes, respectively. The improved varieties viz, Alphonso, Amrapali, Bombay Green, Chousa, Dahiyar, Dashehari, Gajaria, Langra, Mallika, Safeda and Sehroli bear the higher total soluble solids content and thus, appeared better in taste. Similarly, thirteen landraces having high estimates of total soluble solids appeared promising in taste. The total sugars content in the pulp of the mango fruits decides the general acceptability by the consumers. The total sugars content was noted low $(<12 \%)$ in twelve genotypes, medium (12-16\%) in twenty genotypes and high $(>16 \%)$ in sixteen genotypes. Landraces namely, SBM 01-4. SBM 01-6, SBM 01-9, SBM 01-10, SBM 01-13, SBM 0114, SBM 01-15, SBM 01-30, SBM 01-36 and SBM 01-37 along with improved varieties viz, Alphonso, Amrapali, Bombay Green, Chousa, Dashehari, Gajaria, Langra, Safeda and Sehroli possessed higher contents of total sugars. The total acidity in the fruits of selected genotypes was low $(<0.30 \%)$, medium (0.30-0.40\%) and high (>0.40\%) in eleven, fourteen and twenty-three genotypes, respectively. In general, the lower estimates of total acidity are preferred for consumption of ripe fruit. Six landraces of Bhopal division along with Alphonso, Dahiyar, Gulabkhas, Langra and Sinduria possessed low total acidity contents in the fruits. The ascorbic acid or vitamin $\mathrm{C}$ was found low (<100 mg/100 g pulp), medium (100-140 mg/100 g pulp) and high (> 140 $\mathrm{mg} / 100 \mathrm{~g}$ pulp) in fourteen, sixteen and eighteen genotypes, respectively. Ten landraces along with eight improved varieties like Dashehari, Neelum and Bombay Green exhibited high estimates of ascorbic acid. The observations on quality characters of fruits revealed that Amrapali, Dashehari, Alphonso, Mallika, Chousa, Bombay Green, Sehroli, SBM 011, SBM 01-9, SBM 01-10, SBM 01-11, SBM 01-12, SBM 01-35, SBM 01-36 possessed better skin and pulp colour, high total soluble solids, reducing and 
non-reducing sugars, low acidity and high ascorbic acid contents, thus, appeared promising for table consumption. Landraces SBM 01-2, SBM 01-3, SBM 01-4, SBM 01-20 and SBM 01-22 having high total acidity and high total chlorophylls were found suitable for pickle purpose.

The direction of genotypic and phenotypic correlation was mostly same in two years of analysis, but the magnitude of genotypic correlation was in general, higher than phenotypic correlation. It may be due to masking influences of environmental characters. Similarly, the nature of both, genotypic and phenotypic correlations were found mostly same in two years and pooled over the years, but their magnitudes were considerably different. It revealed the inherent association among different characters but phenotypic expression was influenced by the ambient climatic conditions prevailed in two years. The environmental correlations may be of least importance to a horticulturist, but they give an idea to what extent different quality characters of fruits were influenced by the climatic conditions.

Table 1: Mean, range and promising genotypes for fruit quality in mango over two years

\begin{tabular}{|c|c|c|c|c|c|}
\hline \multirow[t]{2}{*}{ Characters } & \multicolumn{2}{|c|}{ Range } & \multirow[t]{2}{*}{ Mean } & \multirow[t]{2}{*}{ CD 5\% } & \multirow[t]{2}{*}{ Promising genotypes } \\
\hline & Min. & Max. & & & \\
\hline $\begin{array}{l}\text { Total soluble } \\
\text { solids }\end{array}$ & 10.70 & 23.48 & 18.50 & 0.61 & $\begin{array}{l}\text { Alphonso, Amrapali, Bombay Green, } \\
\text { Chousa, Dashehari, Langra, Mallika, } \\
\text { SBM 01-20, SBM 01- 23, SBM } 01-25 \text {, } \\
\text { SBM } 01-24 \text { and SBM } 01 \text { - } 19\end{array}$ \\
\hline Reducing sugar & 1.67 & 5.81 & 3.67 & 0.23 & $\begin{array}{l}\text { Chousa, Dashehari, Langra, Mallika } \\
\text { SBM 01-20, SBM 01- 23, SBM } 01-25 \\
\text { and Alphonso }\end{array}$ \\
\hline $\begin{array}{l}\text { Non-reducing } \\
\text { sugar }\end{array}$ & 6.07 & 14.97 & 10.73 & 0.10 & $\begin{array}{l}\text { Amrapali, Sihroli, Dashehari, Langra, } \\
\text { SBM 01-20, SBM } 01-24 \text { and SBM } 01 \\
-19\end{array}$ \\
\hline Total sugars & 7.81 & 20.13 & 14.41 & 0.16 & $\begin{array}{l}\text { SBM 01-4. SBM 01-6, SBM 01-9, SBM } \\
\text { 01-10, SBM 01-13, SBM 01-14, SBM } \\
\text { 01-15, SBM 01-30, SBM 01-36, } \\
\text { Alphonso, Amrapali, Bombay Green, } \\
\text { Chousa, Dashehari, Gajaria, and } \\
\text { Langra. }\end{array}$ \\
\hline Total acidity & 0.23 & 0.53 & 0.38 & 0.04 & $\begin{array}{l}\text { SBM } 01-3 \text {, SBM 01- 4, SBM 01-22, } \\
\text { SBM 01-20, Alphonso, Dahiyar, Langra } \\
\text { Gulabkhas, and Sinduria }\end{array}$ \\
\hline Ascorbic acid & 60.00 & 170.83 & 118.07 & 10.78 & $\begin{array}{l}\text { SBM 01-24, Sindurir, Dashehari, } \\
\text { Neelum, Bombay Green, Gulabkhas } \\
\text { and SBM } 01-37\end{array}$ \\
\hline Chlorophyll a & 0.06 & 2.54 & 0.63 & 0.01 & $\begin{array}{l}\text { SBM 01- 36, SBM 01- } 26 \text { and SBM } \\
01-10\end{array}$ \\
\hline Chlorophyll b & 0.06 & 0.89 & 0.21 & 0.01 & $\begin{array}{l}\text { SBM 01- 36, SBM 01- 26, SBM 01- 10, } \\
\text { Dashehari and SBM 01-3 }\end{array}$ \\
\hline Total chlorophylls & 0.13 & 3.43 & 0.85 & 0.05 & $\begin{array}{l}\text { SBM 01- 26, SBM 01-5, SBM 01- } 10 \\
\text { and SBM 01- } 36\end{array}$ \\
\hline $\begin{array}{l}\text { Total soluble solids } \\
\text { to total acidity ratio } \\
\text { Total sugars to total }\end{array}$ & 1.17 & 1.47 & 1.30 & 0.05 & Langra \\
\hline acidity ratio & 15.34 & 73.37 & 40.25 & 6.18 & Alphonso \\
\hline
\end{tabular}




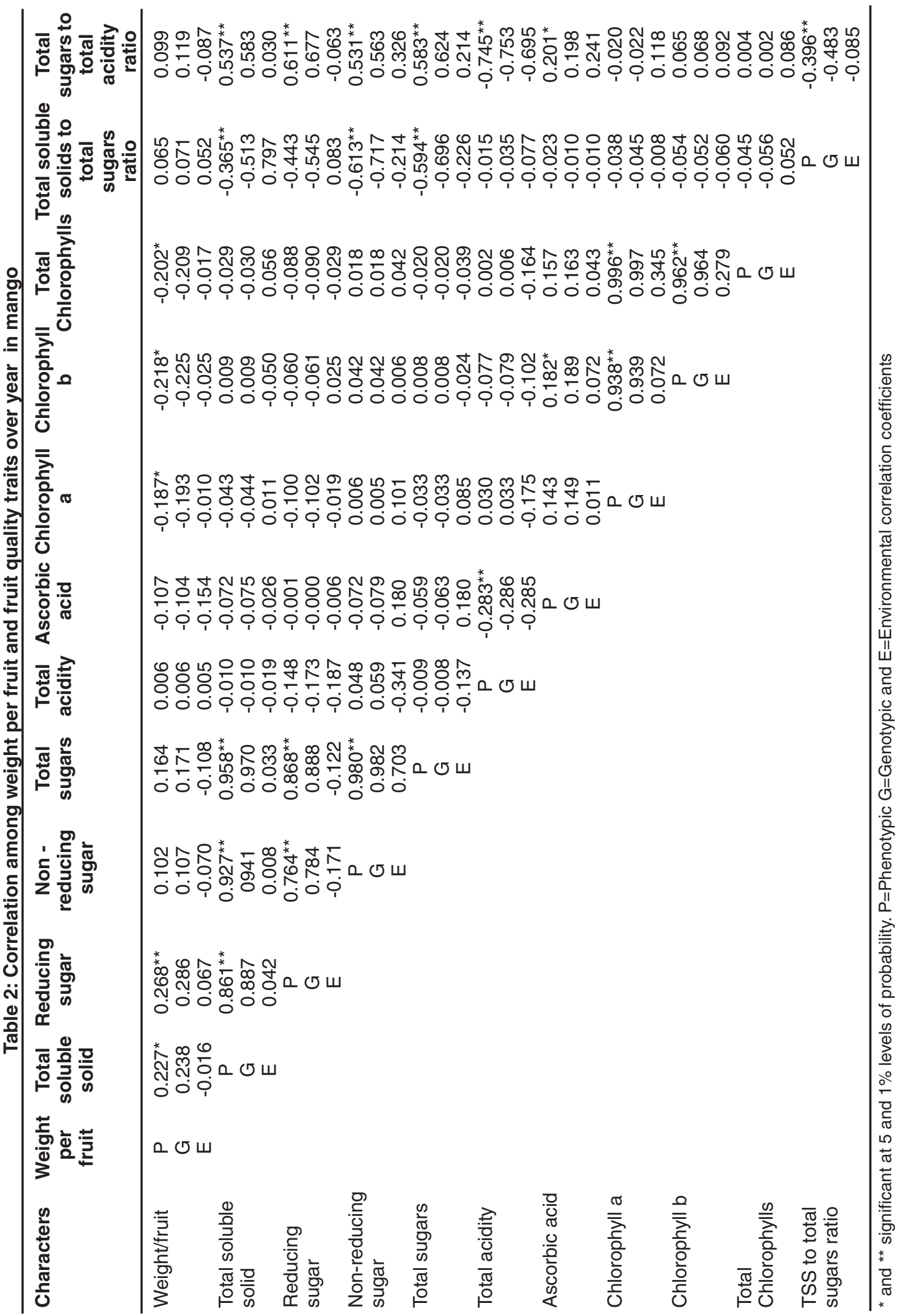




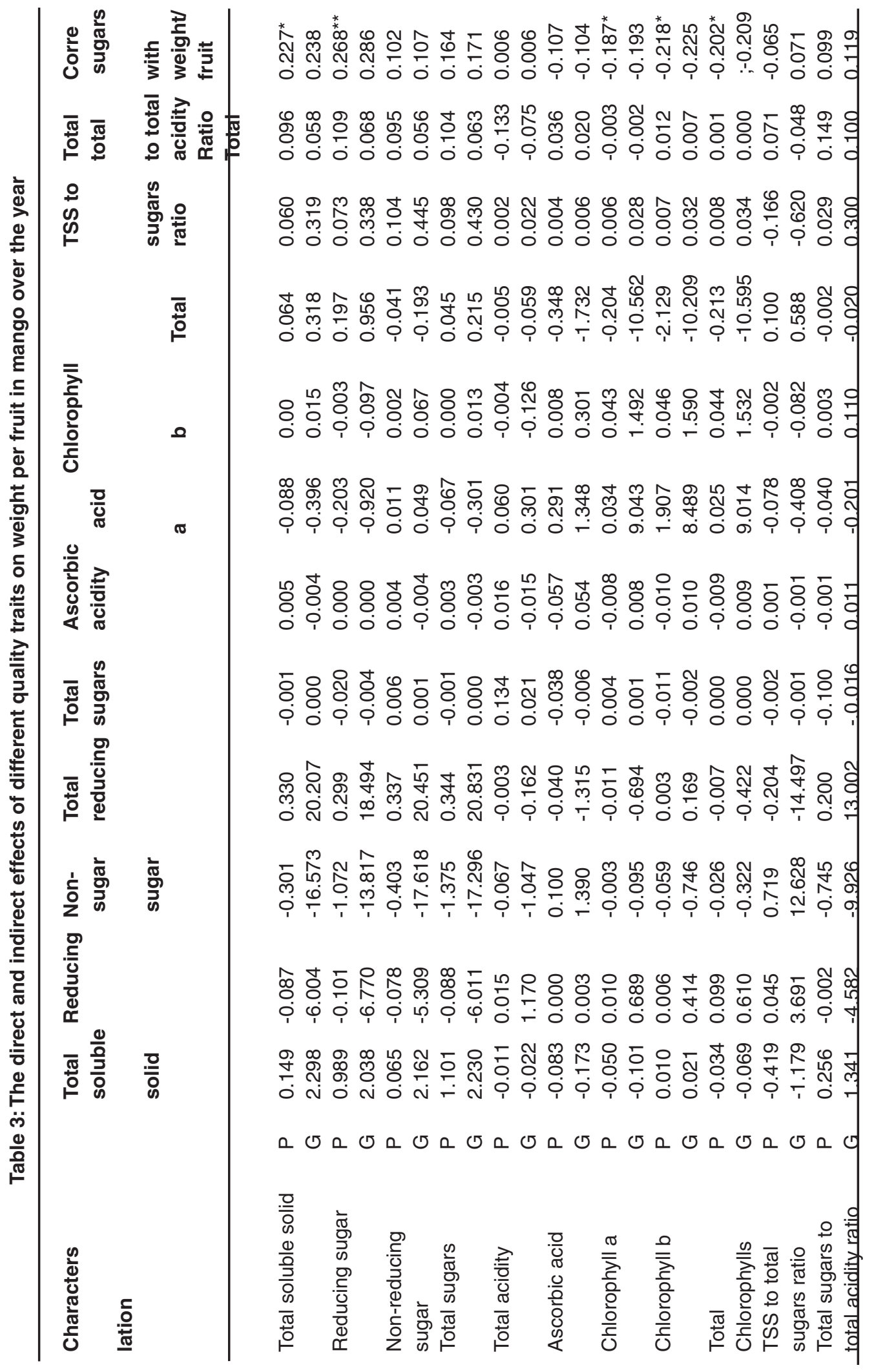


Reducing sugar and total soluble solids were positive and significantly correlated with fruit weight. Similarly, total soluble solids were positively and significantly associated with reducing sugar, non-reducing sugar, total sugars and total sugars to total acidity ratio (Table 2). Reducing sugar, non-reducing sugar and total sugars were also positively and significantly associated among them whereas, total soluble solids to total sugars ratio was negatively and significantly associated with reducing sugar, non-reducing sugar and total sugars. The association between total acidity and ascorbic acid was positively associated with chlorophyll b and total sugars to total acidity ratio. Satyam et al. (1986) has also reported positive and significant association of titratable acidity, total sugars content, ascorbic acid and reducing sugar content in mango.

Path coefficient analysis considering weight per fruit as independent variable revealed that total soluble solids, reducing sugar, non-reducing sugar, total acidity and total soluble solids to total sugars ratio had direct positive bearing on weight per fruit. The direct contribution of total sugars, ascorbic acid, chlorophyll a and b was negative but, total sugars contributed indirectly via total soluble solids, reducing sugar, non-reducing sugar and total soluble solids to total sugars ratio. The present study suggests that total soluble solids, reducing sugar, non-reducing sugar, total sugars to total acidity ratio exerted direct contribution towards the fruit weight in mango. The residual effects observed in different sets of path analyses may be due to environmental influence, which are beyond the control under limit of the present study or the characters, which are not taken into consideration.

An overall observations quality characters of fruits showed that Amrapali, Dashehari, Alphonso, Mallika, Chousa, Bombay Green, Sehroli, SBM 01 1, SBM 01-9, SBM 01-10, SBM 01-11, SBM 01-12, SBM 01-35, SBM 01-36 possessed better skin and pulp colour, high total soluble solids, reducing and non-reducing sugars, low acidity and high ascorbic acid contents, thus, appeared promising for table consumption. Landraces SBM 01-2, SBM 01-3, SBM 01-4, SBM 01-20 and SBM 01-22 having high total acidity and high total chlorophylls were found suitable for pickle purpose. Reducing sugar and total soluble solids were positive and significantly correlated with fruit weight. Similarly, total soluble solids were positively and significantly associated with reducing sugar, non-reducing sugar, total sugars and total sugars to total acidity ratio. Reducing sugar, nonreducing sugar and total sugars were also positively and significantly associated among themselves. Among them, total soluble solids, reducing sugar, non-reducing sugar, total sugars to total acidity ratio exerted direct contribution towards the fruit weight in mango.Thus, these quality traits can be modified genetically along with fruit weight in mango.

\section{REFERENCES}

1. A.O.A.C., Official Methods of Analysis (11 th edn.) Association of Official Agricultural Chemists, Washington, D.C, 1970.

2. Dwivedi, A.K. and Mitra, S.K., Metroglyph analysis of fruit quality traits inlitchi (Litchi chinensisSonn.) Indian J. Hort. 2003; 60: 318321.

3. Dubios, M.; Gilles, K.; Hamilpton, J.K.; Rebers, P.A. and Smith. F, A Colorimetric method for determination of sugars and related substances. Analytical Chemistry 1956; 28 : 350-356.

4. Jayraman, J., Laboratory Manual in Biochemistry . Willey Eastern Pvt. Ltd., New
Delhi, 1981.

5. Plummer, D., An Introduction to Practical Biochemistry . Tata McGraw Hill Publishing Co. Ltd., New Delhi. 1999; 180.

6. Saini, R.S.; Sharma, K.D.;Dhanhar, O.P. and Kaushik, R.A., Laboratory Manual of Analytical Techniques in Horticulture, Agrobios, Jodhpur, India, 2001.

7. Satyam, S.H.; Chaplin.G.R. and Willcox, M.E., An assessment of fruit quality of various mango cultivars. Proceedings of $1^{\text {st }}$ Austrialian Mango Research Workshop.pp 1986; 324333.

8. Shrivastava, S.S.; Asati, K.P.; Patel, M.P.; 
Tiwari, B.L. and Bhadauria, U.P.S. 1987.

9. Evaluation of mango varieties in Madhaya Pradesh.Indian J. Hort. 44: 197-201.

10. Singh, D.B., Improvement of mango (Mangiferaindica L.) for regular and early fruiting in Andaman. Indian J. Agri. Sci. 2002I
72: 631-63.

11. Yadav, K.S.; Singh, M. and Yadava, H.S., Genetic variability and correlated response for physico-chemical traits in mango.Crop Res. 1995; 9: 277-282. 